\title{
La emergencia metafórica y propensión a aprender de preescolares en Chile y Brasil
}

\author{
Ana Paula Sánchez Garbini ${ }^{1}$ \\ Doctoranda del Programa de Doctorado en Educación, Universidad de La Serena, \\ Chile. Email: apsgarbini@gmail.com
}

\begin{abstract}
Resumen: Este artículo devela mi intencionalidad como educadora de provocar nuevas reflexiones desde el nuevo paradigma, considerando mi intencionalidad personal y profesional, y finalmente considerando las intencionalidades sociales que en este caso se evidencian en mi investigación acerca de la emergencia metafórica preescolar de un párvulo chileno y un brasilero. Desde este planteamiento y de los encuentros con los preescolares en el aula propongo una propuesta alternativa hacia la educación de este siglo.

Palabras clave: emergencia metafórica, educación infantil, propensión a aprender, intencionalidad doctoral.
\end{abstract}

\section{The metaphorical emergency and propensity to learn of preschoolers in Chile and Brazil}

\begin{abstract}
This article reveals my intent as educator to provoke new thinking from the new paradigm, considering my personal and professional intentions, and finally considering social intentions that in this case are evident in my research about the metaphorical preschool emergency of a chilean and brazilian infant. From this approach and the encounters with preschoolers in the classroom, I propose an alternative approach towards the education for this century.

Key words: metaphorical emergency, childhood education, propensity to learn, doctoral intentionality.
\end{abstract}

\section{A emergência metafórica e a propensão a aprender das crianças no Chile e Brasil}

Resumo: Este artigo revela a minha intenção como educadora de provocar novas reflexões a partir do novo paradigma, considerando as minhas intenções pessoais e profissionais e, finalmente, considerando as intenções sociais, neste caso, evidenciadas na minha pesquisa sobre a emergência metafórica de uma criança chilena e uma brasileira na sala de aula. A partir desta idéia e dos encontros profissionais com crianças no jardim infantil, proponho uma abordagem alternativa para a educação deste século.

Palavras-chave: emergência metafórica, educação infantil, propensão a aprender, intencionalidade doutoral. 


\section{Introducción}

Como fonoaudióloga nativa brasileña y ejerciendo mi profesión en Chile durante varios años, he tenido la oportunidad de mezclar mi historia subjetiva, la inmersión en ambientes escolarizados en Brasil y Chile y el curso doctoral en educación de manera placentera y creativa.

Tal libertad se distancia mucho de los ambientes escolarizados cerrados vividos durante toda mi infancia y juventud en Brasil y los ambientes escolarizados preescolares en Chile en los que he trabajado durante la última década. Esta semejanza detectada aproxima mis traumas escolares de claustro físico y emocional haciéndome propender a realizar acciones de cambio creadoras de sinergias educativas para hoy y mañana.

La relevancia de mi transformación subjetiva integrando un cierto poder educativo $^{2}$ es el de haber trillado un camino desde mis experiencias, vivencias y conceptos paradigmáticos como holismo y complejidad, a las necesidades aplicables en el entorno social glocal -local y global- que culminan en mí proyecto de investigación doctoral acerca de la emergencia metafórica en las culturas chilena y brasilera.

\section{Emergencia metafórica y propensión a aprender en dos culturas}

\section{Indagaciones del proyecto}

"Si pudiésemos recuperar para la sociedad humana, la natural confianza de los niños en sus mayores, tal sería el mayor logro de la inteligencia operando en el amor, jamás imaginado" Rolf Behncke

La confianza desde el amor expresada en la cita de Rolf Behncke, plasma en la educación una necesaria manera de mirar el quehacer cotidiano del educador con el educando en el ambiente escolarizado desde la etapa preescolar. Tal hecho nos atrae a buscar elementos emergentes y no esperados en el discurso infantil, como lo hace la escuela, para inspirar nuevas maneras de mirar el aprender y nuevas formas de ser-hacer formales en el aula, que revela estructuras estrechamente repetidas desde el Jardín infantil.

Chile y Brasil, por ejemplo, representan dos culturas occidentales inmersas en la "racional prisa" instaurada en sus formas de ser-hacer como parte del paradigma racionalista ${ }^{3}$. Dentro de este tendencioso orden, hemos privilegiado la objetividad y, por lo tanto, la literalidad expresiva en pro de la razón y de la eficiencia máxima en el aula. 
Al estar algunas décadas encerrados en el claustro escolar, (des)aprendiendo "a fuerza" los contenidos exigidos y muchas veces sin poder manifestar plenamente nuestras emergencias discursivas subjetivas y creativas, es que elegí la emergencia metafórica como una huella del aprender polifacético ${ }^{4}$. Tal huella colaboraría a la apertura de posibles entendimientos educativos renovados, ampliando la manera de ser-estar-hacer preescolar. Hemos escogido el sentido de ser educador-educando vitalicios y no obligados a cumplir etapas en finitos espacios y tiempos escolares, lo que nos invita a considerar la vida preescolar sinérgica, ya que proyecta relaciones que son posibles al educar y no solamente las relaciones preestablecidas como ocurre actualmente desde el jardín infantil hasta la universidad.

Muchos autores (Arellano, 2005; Calvo, 2006; Guillaumín y Ochoa, 2009) han trabajado en la reflexión sistemática de nuevas posibilidades para la educación escolarizada actual, en donde prevalece el uso exclusivo racional y parcelado que excluye la intuición, la metáfora, la ambigüedad y el pensamiento analógico, que caracterizan el aprendizaje polifacético.

Entonces, los educadores preocupados por cumplir el programa dentro del espacio-tiempo permitido en los jardines infantiles y escuelas, no les pueden hacer caso a las emergencias, primero por desconocer su significado e importancia y, segundo, porque no hay espacio-tiempo para "distracciones”. Creemos que la educación es una oportunidad para que los individuos inventen conocimiento por sí mismos y transformen lo que se ha establecido en el pasado contribuyendo entonces a la elaboración de un nuevo saber colectivo. Esto se favorece ofreciendo un ambiente de exploración creativa (Gardner, 1997:127), que en el jardín infantil se expresa en movimiento discursivo y físico. Hoy en día es frecuente que dichos momentos recreativos, no sean considerados formativos.

La metáfora, como elemento propiciador de aprendizajes, no está considerada en los planes y programas preescolares de las instituciones chilenas y brasileñas; sin embargo en el ámbito de la comunicación verbal de las Bases Curriculares de la Educación Parvularia en Chile, se aborda, por ejemplo, la capacidad de simbolización, es decir, hacer presente lo que no está presente, para que los niños vayan “...adquiriendo distintos niveles de complejidad, que les permite evocar las cosas, hechos, ideas a través de diferentes medios” (Módulo VI. Sesión 1:97). Lamentablemente, la emergencia metafórica en el aula, que alimenta tales aprendizajes, no se ha sistematizado en Chile o en Brasil. Dado que el lenguaje crea realidad (Maturana y Varela, 2007) debemos observar cómo los párvulos son en y con el lenguaje para descubrir sus emergencias metafóricas.

Si observamos el hacer en y con el lenguaje en el aula preescolar podremos descubrir las emergencias de los párvulos: uno chileno en un Pre-kinder en un establecimiento público y un brasileño en un Jardín Infantil particular. De esta manera, daremos cuenta de que si la naturaleza infantil trae emergencias en el discurso, podemos aprovecharlas en el contexto del 
aula y no solamente tomarlo cómo recreación o de tono informal.

Reflexionando acerca de las necesidades educativas del paradigma vigente, ávido de innovaciones formales pero siempre enmarcadas en la linealidad, nos hemos percatado de que no existe un registro sistemático de la emergencia ${ }^{5}$ metafórica en el aula, siendo que se trata de una fuente subjetiva, creativa y polifacética del aprender infantil. Frente a la escolarización, que espera respuestas secuenciadas y literales por parte de los alumnos, la creatividad de la emergencia metafórica es descartada por el desconocimiento de sus profundas implicaciones lingüísticas y cognitivas así como por no comprender que ocurren de manera constante en la vida infantil en el aula y fuera de ella.

En la vida adulta observamos las creaciones poético-metafóricas tempranas que nos hace imaginar: ¿Qué lazos estarán tejiendo para cada nueva creación intuitiva y emergente que emociona y significa en el mismo ciclo de sus vidas? Los versos informales nos vuelven a emocionar y a enseñar. ¿Por qué, entonces la escuela no permite que emerja la creatividad presente en los movimientos discursivos enriqueciendo el tejido transformador del aprender humano desde el amor y la confianza?

Las primeras expresiones metafóricas infantiles revelan, a través del pensamiento analógico las ideas, definiciones y reflexiones humanas del mismo modo como las metáforas adultas dan testimonio, en y a través de ellas, de la danza dual entre la certidumbre y la incertidumbre presentes en nuestra complejidad humana.

Sinergizamos ${ }^{6}$ gracias a nuestras creaciones intuitivas infantiles. En cada expresión infantil enunciada y cargada de motivaciones y significados emergen pensamientos y aprendizajes que en muchas oportunidades no se reconocen en la educación preescolar.

Para sinergizar pareciera suficiente que el enunciado nos guíe hacia a una aventura a través de los procedimientos discursivos: situación, palabras, gestos, los enunciadores y enunciatarios (profesores, alumnos, etc.). Por ejemplo la caída del calendario lleva a Joaquín (párvulo chileno) a sinergizar su experiencia y reflexión en la metáfora “Se tiró un piquero". Esto ocurre en un instante que si no lo descubrimos y aprovechamos su potencial educativo se pierde definitivamente. Este "instante educativo" implica estar atento y fluir con el otro mientras la emergencia metafórica ocurre en el aula. De este modo se podría favorecer la unión de sentidos literales con los metafóricos así como nuestras verbalizaciones cotidianas e informales fluyen paradojal y simultáneamente de manera ordenada y caótica.

Nuestra naturaleza humana hace emerger este rizoma metafórico como parte de la propensión a aprender por parte del niño en diferentes culturas. La metáfora podría indicar, así como una huella, la riqueza de relaciones que establece el preescolar de acuerdo a su experiencia en el mundo, lo que nos 
anima como sanadores-educadores ${ }^{7}$ a observarlas como elemento potencial de relaciones complejas por parte del niño, que siendo alimentada y no inhibida en el proceso educativo, le servirá para toda la vida.

Creemos que la metáfora es un medio natural para estructurar el pensamiento que nos permite la realización de asociaciones creativas que van desde las primeras comparaciones denominativas infantiles (Martí, 1988) hasta las que realizamos en la vida adulta. Dado que los desplazamientos discursivos - representados por cambios de tema, género, mundo hasta el de punto de vista (metáfora) - se mueven aleatoriamente de uno a otro, sin orden previo sino que emergente, nos ha llevado a hablar de emergencia metafórica. Consideramos que permitir el fluir discursivo en el aula propicia la trascendencia de significados primigenios, lo que se observa en los desplazamientos discursivos, por ejemplo de tema, género, mundo y de punto de vista (François, 1993), representado en este proyecto por la emergencia metafórica para dar cuenta si ¿ estaremos inhibiendo el aprender infantil en el contexto escolar, ambiente creado para tal acción?

A partir de estos hechos reflexionamos de qué manera, en pleno proceso de desarrollo del lenguaje, emergen los desplazamientos de punto de vista (metáfora) que nos sensibilizarían acerca de sus relaciones en el proceso formal preescolar, germinando consciencias educativas renovadas. Estimamos que la relevancia de la educación preescolar no debe tener tan solo un valor asistencial o de preparación para las siguientes etapas, mas sí un valor propio de ser-estar-hacer infantil propicio de trascendencias $^{8}$ inimaginables.

Si los niños metaforean con frecuencia y eso les permite configurar su mundo nos pareció interesante como problema educativo la necesidad de develar ¿Cuáles son los procedimientos discursivos utilizados por el preescolar durante la emergencia metafórica en el aula?

\section{Metodología del proyecto}

El presente proyecto de investigación contempló el estudio de 2 sujetos, un niño chileno y un niño brasilero, en los que estudiamos la emergencia metafórica en el aula. Ambos sujetos de entre 4 y 5 años de edad, asisten a escuela pública y privada respectivamente en Chile y Brasil. A través de la observación y grabación en audio y video de los sujetos en el aula, realizamos la exploración, descripción y análisis cualitativo de las emergencias metafóricas de los enunciados en cada establecimiento escolar en ambas culturas.

El enfoque cualitativo fue de base etnográfica porque en ambas culturas, Chile y Brasil, procederemos a explorar, a partir de los registros en video de las respectivas aulas, "la declaración explícita sobre cómo actúan los miembros de un grupo social” (Wolcott, 2007:133): en este caso un niño chileno y un niño brasilero en su contexto escolar. Por enfocar a la educa- 
ción y los elementos lingüísticos culturales, como procesos socioculturales, representados en este trabajo por la emergencia metafórica de los enunciados de los sujetos, evidenciaremos los movimientos discursivos (François, 1996) de cada cultura en las transcripciones ortográficas ${ }^{9}$ correspondientes a las grabaciones audibles de video en el aula.

Por otra parte, el presente estudio corresponde a una aproximación metodológica no experimental y cualitativa, que se ha basado en los fenómenos en su ambiente cultural, fundamentándose en los datos empíricos reales, para luego describirlos en la base etnográfica, buscando las emergencias metafóricas en los enunciados de ambos sujetos en el aula y en ambas culturas. El diseño contempló, además, la recolección de datos en un tiempo previamente establecido caracterizándolo cómo un estudio transversal (Hernández, Fernández y Baptista, 2005). El tiempo instituido fue de 9 sesiones de grabación, correspondiente, en ambos casos, a 45 minutos de hora/aula.

Debido a que este proyecto se desarrolla en el contexto espaciotemporal del proyecto "Asombros Educativos infantiles y propensión a aprender” (Fondecyt $\left.n^{\circ} 1110577\right)$, se le es asignado dos años para ser realizado, por lo que optamos por delimitar hasta 10 horas a los registros en video, para lograr realizar los respectivos análisis de datos dentro del plazo estipulado. Consideramos además que las horas grabadas atienden al objetivo general del proyecto de establecer la emergencia metafórica en el aula y en ambas culturas. Cabe explicitar que aumentar el número de horas grabadas, posibilitaría incrementar los posibles análisis específicos de los tipos de emergencias metafóricas, pero escaparía de los propósitos de este estudio.

Los registros de la emergencia metafórica como desplazamiento ${ }^{10}$ en ambos preescolares y en diferentes culturas, considerando la manera de hacerse sujeto socialmente en y con el lenguaje, y dentro del marco de nuestro objetivo, se adhiere al paradigma interpretativo de las ciencias sociales (Vasilachis, 2009), ya que centra la mirada en el contexto empírico. Concuerda además con el planteamiento interpretativo propuesto por François (1993) en que los análisis son: “Situaciones de interpretación...que no consisten en buscar el sentido oculto bajo el sentido claro, mas, al contrario, en explicitar el sentido que cada uno puede encontrar en estos textos. ...el intérprete es aquí como uno de los participantes del diálogo, un sujeto genérico-particular, que puede compartir con éxito su punto de vista” (François, 1993: 135).

De la misma manera, se conforma la elección metodológica cualitativa de explorar, describir e inferir relaciones educativas en ambos sujetos de estudio, considerando la subjetividad y la creatividad del preescolar, evidenciadas empíricamente en el aula, creyendo que “el pensamiento sí orienta al sujeto respecto de él mismo y del mundo, le permite hacer predicciones, le sirve de base para actuar y le confiere sentido a su experiencia. Sus explicaciones son situadas en un contexto social y cultural; por lo mismo, 
le permiten interactuar con otros, ser miembro de una comunidad, con la cual mantiene una recíproca influencia” (Catalán, 2010:74).

Esto significa en este trabajo que, la emergencia metafórica como elemento de relaciones conceptuales y lingüísticas, enunciadas verbalmente, conlleva entonces, ese poder enunciativo del niño en el aula, haciéndose sujeto, así como en los ambientes familiares e informales, revelando si emergen y cómo lo hacen en el contexto del aula.

Se realizó la observación etnográfica, considerando el contexto y focalizando las expresiones espontáneas de los niños, en conversaciones con otros niños y con la educadora mientras realiza las actividades cotidianas escolares.

Luego de realizar los registros en video del niño en el contexto escolar chileno y brasilero, mientras participa en el aula, se utilizó la transcripción $^{11}$ de las interacciones lingüísticas facilitando el análisis. Al final de los registros en video y respectivas descripciones etnográficas, el material fue analizado a través del programa Atlas- $\mathrm{ti}^{12}$ a modo organizacional de los tipos de desplazamientos discursivos realizados.

\section{Resultados y discusión}

La creatividad del metaforear ${ }^{13}$ infantil en aula fue establecida en este proyecto evidenciando nuestros primeros pasos propendiendo a aprender desde el sesgo metafórico que une la razón o nuestros conocimientos causales físicos, biológicos y emocionales a nuestros sueños o ideas fantasiosas, en donde establecemos nuevas relaciones moviendo el descubrir humano.

Las emergencias metafóricas establecidas en ambos párvulos culminaron a partir de movimientos discursivos o enunciados aleatoriamente creados y que fueron detectados en momentos de distracción frente al profesor, de movimiento corporal del párvulo y de concentración en actividades en donde había un ensimismamiento hacia el trabajo. Fueron necesarios varios cambios de tema, género, mundo hasta culminar la emergencia del punto de vista ${ }^{14}$ - metafórico - durante los registros etnográficos.

Tal libertad discursiva necesaria para establecer relaciones sigue siendo podada en los ambientes escolarizados de manera sistemática por las necesidades imperantes de control del espacio y tiempo instauradas en el paradigma industrial-cartesiano. Por haber experimentado en primera persona el claustro escolar y hoy sentir la libertad responsable de colaborar para que otros seres humanos preescolares tengan la oportunidad de metaforear motivados por ambientes más abiertos o de mayor acercamiento entre ellos mismos en el discurso y hacia la naturaleza, que me he entusiasmado con la posibilidad de investigar este tema, provocando nuevas miradas educativas. 


\section{Influencia holística y de la cosmovisión educativa}

La visión holística de los contextos me ha acercado al pensar metafórico adulto que me persigue y entusiasma. Digamos que el viento me trajo al tema metafórico y por no resistir infinitamente ante él sosiego en la creación. Puedo hoy dejarme entregar a este viento, primero porque me lo han permitido y segundo por haber descubierto de que si me equivoco pronto encontraré otro camino. He sido guiada por las referencias encontradas junto a los encuentros con buenos familiares, profesores y educadores que me propiciaron soporte emocional y de alguna manera informacional.

Mi historia me ha alertado de que el sendero no se descuida, así se facilita el proceso que conlleva el tan costoso dejar que los eventos sucedan. Pero qué hacer con esta fatal impaciencia que nos tira lejos, luego de tomar decisiones cargadas de explosiones y arrepentimientos. Bueno, acudo al pensamiento chino de pensar la situación, antes que el yo-sujeto que nos cuesta mucho: me exigí cumplir mi estricto orden a mí favor. He fluido entre mundos y personas al mismo tiempo lejanas en cultura y profesión pero muy cercanas en la humanidad en el Cosmos. Tal posibilidad puede ser alimentada en nuestras aulas preescolares para que se utilice el orden, o sea una cosa por vez, a favor de la creación y no como poda de ideas como en la escuela de hoy.

Las sincronías personales en los contextos sociales pueden relacionarse a la coherencia matricial descrita por Lazlo (2009) en donde también nos intercomunicamos desde el campo o del pleno Cósmico. Tales investigaciones hechas por científicos aportan a la renovación del paradigma mecánico hacia el paradigma cuántico. Entonces la sensación y la posibilidad de que el tema de investigación me haya encontrado llegando desde el viento, guardaría relación con la causalidad descendiente descrita por Lazlo (2009: 156) ya que si todas las cosas en el espacio-tiempo están conectadas, existiría la influencia causal de sistemas íntegros en cada una de sus partes. Si hablamos a nivel cuántico esto crearía un entrelazamiento de partículas dentro del sistema de coordenadas, lo que propiciaría en el mundo vivo coherencia y correlación en y entre los organismos y ecologías. ¡Sí, el tema de la emergencia metafórica podría entonces haber llegado volando!

He decidido hacer una investigación formal porque las vueltas del torbellino del vivir nos arrastran y de pronto optamos por un camino. Digamos que en este jardín de caminos bifurcados (Borges, 1941) elijo la curiosidad humana hacia el ser humano más allá de mis fronteras Fonoaudiológicas y elijo el camino de la investigación primordialmente cualitativa en educación porqué aporta al fenómeno subjetivo que transfiere y conecta el ser-estar-hacer local y cósmico a través de las descripciones y vivencias personales. Esta es una explicación causal ascendiente pero atenta y aún intensamente emocionada, considero que complementa una posible explicación causal descendiente, repensada anteriormente con las lecturas de Lazlo y que, nos mueve hacia un sendero fenomenológico cualitativo de las cualidades personales del individuo en el Cosmos. Así opto por realizar 
el estudio de caso etnográfico de un niño chileno y un niño brasilero.

El mismo oficio de vivir nos lleva a explorar caminos y la investigación científica nos posibilita una manera de seguir convenientemente un modelo para lograr descubrir lo que nuestra intuición y experiencia nos trae a la conciencia vivencial. La metodología formal nos dará la seguridad en donde apoyarse solamente para seguir creciendo en el Cosmos. Para vivir en la humanidad e investigar curioseando el mundo cuesta obrar en él, el apoyo solamente ampara no lo resuelve por magia. Los chinos nos enseñan acerca de una categoría del desarrollo en curso, en donde el proceso es por sí sólo la entera realidad o su Tao (Jullien, 2006:73).

La motivación para curiosear investigando el entorno tan característica de los preescolares, se ha evidenciado en este proyecto de investigación justamente por el movimiento físico y discursivo exploratorio temprano que ejecutan creando emergencias metafóricas que modifican el entorno en donde ellos puedan ser-estar-ocurriendo (Gonzáles e Illescas, 2002). El oficio de vivir de ambos niños en diferentes culturas como la chilena y brasilera fue evidenciada por los movimientos discursivos, en donde ellos obran sistemáticamente al dar sentidos en las diversas situaciones dentro del aula creando nuevos mundos que operan de acuerdo al sujeto que conoce, o como uno ve tal realidad (Kant, 1938). Creer en estos mundos impulsa el investigador y al niño a poner de su cosecha, actuando en su humanidad y en equilibrio con lo que ya se lleva hecho.

\section{La propensión a aprender a partir de la experiencia preescolar en Chile y Brasil}

Un poeta o matemático en almas adulta o preescolar manifiestan su ser de maneras similares: ambos agarran sus dominios o conocimientos, los mezclan a su imaginación y cuando confiados en su inteligencia intuitiva (Gladwel, 2008), los hace propender a la creación. La emergencia metafórica entonces, que reúne la razón y la imaginación, sintetiza y alimenta el camino del aprendiz que investiga el mundo asombrándose. Para que aquello sea posible es crucial que la accesibilidad espacio-temporal dentro del contexto escolar provoque el descubrir por parte del niño.

Los registros etnográficos de este proyecto han evidenciado la búsqueda incesante de ambos niños en trascender sus experiencias en el contexto y como el aula restringe tal necesidad humana. Al establecer la emergencia metafórica en aula en Chile y Brasil a través del análisis de los procedimientos discursivos de ambos educandos durante sus actividades en el aula, evidenciamos la potencialidad para que los ambientes escolares construyan espacios y tiempos en donde el movimiento discursivo de colocación de palabras - mise en mots ( François, 1993) - pueda circular entre educandos y educadores en un lugar libre para el movimiento físico - gestos y posturas corporales - y para que los desplazamientos discursivos de 
tema, género, mundo y punto de vista o metafórico emerjan.

Al establecerse la emergencia metafórica en aula en el discurso infantil podemos provocar nuevas reflexiones hacia una innovación en el quehacer educativo en nuestras aulas preescolares. Considerando que los niños utilizan elementos emergentes del contexto, incluyendo los enunciados de otros, para relacionar, asociar y metaforear, lo que es evidenciado en la circulación de enunciados y desplazamientos de tema, género, mundo y punto de vista (François, 1993), hay que explorar estos eventos-contextos que son motivados por los mismos párvulos, evitando imponer temas, conceptos o analogías, ya que tales contenidos fluirán a partir de los intereses del educando.

Considerar los elementos emergentes del contexto se hace necesario para construir un ambiente propiciador de que la circulación discursiva ocurra, juntamente con los movimientos corporales - gestos y posturas propios de los preescolares. Este ambiente involucra el lugar, los educadores, los educandos, todos los objetos presentes desde los muebles hasta los materiales personales y didácticos. Considerando que la emergencia metafórica como desplazamiento de punto de vista ocurre a partir de los desplazamientos de tema, género y mundo, se hace necesario el lenguajear (Maturana y Varela, 2007) juntamente a los movimientos físicos de los párvulos porque su experiencia corpórea les permite aprender los conceptos. Este acceso al sistema conceptual cultural está fijado en la experiencia del mundo (Lakoff y Johnson, 1980). Dado que las conceptualizaciones traen un punto de vista, los niños muestran sus significaciones sobre los objetos de manera literal y simbólica, enunciando desplazamientos de punto de vista (François, 1993) que evidencian el metaforear.

Creemos entonces que el espacio físico circular entre educadores y educandos amplía la posibilidad de contacto ocular, cercanía físico-emocional fraterna, encuentro inter-subjetivo, conexión empática como lo hace la coherencia cuántica ${ }^{15}$ y posibilita al educador una visualización amplia de los educandos. Los movimientos físicos de lugar y discursivo en los enunciados estando abiertos al cambio constante y no castigados manteniéndose estáticos, como parte de la complejidad de relaciones, se beneficiará de la aleatoriedad espacio-temporal. A través del seguimiento temático propuesto ora por el educando, ora por el educador, circulará entre el orden y desorden creando posibilidades de nuevas relaciones construidas entre todos los participantes del grupo humano. De esta manera el orden y la construcción de conocimiento motivados en el ser-estar-ocurriendo llegarán por los ciclos discursivos de educadores con los educandos preescolares; el placer de descubrir aprendiendo en esta propuesta abandona el obligar escolarizado al satisfacer educativo.

Los materiales que promuevan la curiosidad y asombro de los educandos parten de la naturaleza, incluyendo los seres humanos, hasta los objetos utilizados en los espacios escolarizados. La diferencia a destacarse aquí es que el educando busca y realiza asociaciones libres, que 
luego podrán ser mediadas por el educador, desde sus intereses y motivaciones. El material está disponible para que el educando elija y pronto realizará asociaciones conceptuales y emergencias metafóricas en el discurso evidenciadas en el corpus etnográfico.

De acuerdo a la descripción de los resultados se enlistan algunos tópicos relevantes que considero para sugerir propuestas alternativas sobre el valor de la emergencia metafórica en el aula. Lo primero atañe a la propensión de ambos sujetos, con o sin materiales didácticos específicos disponibles, crear emergencias metafóricas como desplazamiento en sus discursos. Ambos párvulos manifiestan movimientos físico - posturales y gestuales - durante la emergencia metafórica que complementan los significados léxicos y emocionales de ambos niños. El carácter exploratorio constante de ambos sujetos, en diferentes contextos culturales, revela que la atención de los sujetos no está aún focalizada como en nosotros, los adultos. Tal hecho promueve asertividad en sus respuestas, aún estando aparentemente distraídos en movimientos físicos y juegos verbales paralelos.

A partir de ambos estudios etnográficos, ambos párvulos participan de diálogos paralelos al tema del aula y siguen estableciendo relaciones que van configurando sus mundos. Es parte de nuestro lenguajear, tanto la distracción, cuanto el discurso generado en él, que complementa el discurso lineal escolar, o aquél en donde se permite un solo tema a la vez y que, en gran parte, es iniciado y controlado por la educadora.

Fundamental para cerrar estas sugerencias es que el educador cuente con motivaciones propias para educar y se involucre en los asuntos infantiles. El adulto conversa con otros adultos en general buscando temas en común. Los adultos que educamos profesionalmente a los niños debemos estar involucrados en sus temas, en caso contrario, tal vez se deba buscar otro tema de conversación. Motivar es estar motivado en este ciclo educativo humano.

\section{Conclusión}

Al establecer la emergencia metafórica en el preescolar en Chile y en Brasil demos cuenta de la síntesis de las ideas y fantasías que reúne lo literal - racional - a lo simbólico - imaginación - creando desplazamientos de punto de vista (François, 1993) evidenciados en el discurso de ambos preescolares. Este hecho amplía el campo de conocimiento del niño, sus asociaciones y emociones revelando la potencialidad educativa al promover desafíos subjetivos, cognitivos y lingüísticos como parte de la propensión a aprender escolar. Las consideradas "distracciones" discursivas en las construcciones verbales como: "La goma se tiró un piquero al agua" (párvulo chileno); "O vento que o céu derrubou a água”16 (párvulo brasilero) dan testimonio de las oportunidades de que los niños inventen conocimientos por sí mismos transformando lo que se ha hecho en el pasado y contribuyendo al saber colectivo. 
La fluidez discursiva en los espacios escolarizados puede lograse con pocos materiales y mucha voluntad. La emergencia metafórica es creadora de relaciones inéditas a partir de lo conocido y los sueños desde la infancia alimentan estas asociaciones que hoy están fuera del programa escolar.

La propuesta alternativa acerca del valor de la emergencia metafórica en aula a partir de ambos estudios de caso guardan relación con el crear espacios y tiempos que promuevan la curiosidad y asombro de los educandos alimentando la relación sinérgica y holística entre enseñanza y aprendizaje (Calvo, 2006) dentro de la libertad discursiva en aula. Es imponderable -desde las evidencias de este trabajo- la necesidad de libertad lingüística en las aulas preescolares actuales fomentando las creaciones subjetivas de los párvulos en su ambiente cultural.

Considerar el entorno, el movimiento físico, discursivo y la mediación del educador con el educando son puntos cruciales de las bifurcaciones relevantes en las aulas preescolares para el siglo XXI en diferentes contextos sociales. 


\section{Notas}

${ }^{1}$ Tesista del Proyecto de Investigación FONDECYT No 1110577 : “Asombros educativos infantiles y propensión a aprender”. El artículo se ha escrito en el contexto de este proyecto.

${ }^{2}$ El poder educativo se caracteriza por una transformación íntima y cíclica de mi consciencia que misteriosamente modifica la actitud y mi vida humana en el Universo. He iniciado la utilización de este término el año 2010, durante los estudios doctorales.

${ }^{3}$ Por subordinarse exclusivamente a la racionalidad, excluyendo la casualidad y los eventos circunstanciales, como las emergencias discursivas, que tal manera de pensar resulta del paradigma cartesiano definido como: "El modo dominante de conciencia en Occidente desde el siglo XVII a la actualidad. Define como real aquello que puede ser analizado o explicado por el método científico. El mundo es visto como una vasta colección de materia y movimientos que obedece a ciertas leyes matemáticas” (Berman 1987:335, citado por Calvo, 2006: 28)

${ }^{4}$ Por considerar el aprendizaje educativo, no escolarizado, polifacético que no excluye el análisis ni la intuición en los procesos educativos, es que consideramos que polifacético significa: “...que podemos aprender varias cosas diferentes a la vez, gracias a la enorme capacidad cerebral. En cambio, el aprendizaje escolar es parcelado y secuencial: uno por vez. El carácter polifacético se vincula estrechamente con la dimensión holística y sinérgica de los procesos educativos” (Calvo, 2006: 37)

${ }^{5}$ Utilizamos el concepto de emergencia desde el pensamiento complejo en donde se considera el tejido de eventos, acciones, interacciones, retroacciones, determinaciones y azares como constituyentes de nuestro mundo fenoménico. Lo que emerge o brota en el discurso humano "...se presenta con los rasgos inquietantes de lo enredado, de lo inextricable, del desorden, la ambigüedad, la incertidumbre...” (Morin, 2005:32). Lo emergente es lo no predecible, al contrario de las predecibles acciones y verbalizaciones escolares exigidas actualmente.

${ }^{6}$ Dado el significado de la acción de dos o más causas cuyo efecto es superior a la suma de los efectos individuales (RAE, 7/02/13) entendemos que la cooperación entre las partes toma movimiento necesitando crearse el verbo sinergizar.

${ }^{7}$ Entendemos que el educar consiste en desvelar las potencialidades de la otra persona. Consideramos que es también sanar debido a su carácter cíclico, transformador e interno de cada ser. Sí el terapeuta debe adaptar las técnicas al individuo según sus necesidades individuales, se convierte en educador ayudando a que cada ser humano pueda dirigir su bienestar. Ahora bien, si el educador estimula la sabiduría para que sus educandos sigan los senderos por su cuenta, también son sanadores y ambos utilizan sus recursos interiores para lograrlo así como desarrollar habilidades prácticas y técnicas. Así sanamos o educamos continuamente creando la vida misma en el ser-estar-ocurriendo.

${ }^{8}$ En este contexto, la trascendencia en términos educativos implica la emergencia metafórica a través del lenguaje subjetivo del niño y su proyección en el tiempo y espacio escolar y educativo. 
${ }^{9}$ Las trascripciones ortográficas del corpus etnográfico contaron, en cada idioma, con códigos previamente establecidos por la investigadora a partir de la bibliografía utilizada en los análisis de corpus lingüístico en español y portugués que facilitaron el proceso de análisis y validación entre los intercodificadores.

${ }^{10}$ La fundamentación teórica- metodológica de los análisis de corpus de la metáfora en niños de 3 a 6 años, es discutida por François que amplía el sentido de la metáfora como desplazamiento (Del Ré, 1998), por lo que optamos por analizar el corpus adscrito a esta perspectiva.

${ }^{11}$ Las transcripciones serán ortográficas una vez que los niños seleccionados hablan de manera clara. Se utilizará la transcripción fonética cuando no ocurra el entendimiento de lo que fue dicho por el niño dentro del contexto escolar y será indicado entre paréntesis ortográficamente su correspondiente.

${ }^{12}$ El programa computacional ATLAS-TI es parte del CAQDAS (Computer Assisted Qualitative Data Analysis Software) y será utilizado en este proyecto como herramienta de apoyo organizacional de análisis cualitativo.

${ }^{13}$ Los niños preescolares metaforean así como nosotros adultos lo hacemos, o sea, crean nuevos sentidos en la vida en el lenguaje: a través de la metáfora unimos los conceptos a nuestros sueños, imaginando contrafactuales y creando lo que vemos y hacemos a nuestro alrededor.

${ }^{14}$ Por ejemplo, el párvulo chileno enuncia: "La goma se tiró un piquero al agua”, creando nuevo sentido en el contexto a partir de que su goma se cae al suelo; el niño brasilero crea nuevo sentido a la lluvia cuando enuncia: "El viento que el cielo derrumbó el agua” (traducción de la autora).

${ }^{15}$ Influencias de energía a través de los biofotones que representan el motor de los procesos biológicos fundamentales en la evolución, desarrollo, diferenciación y degeneración celular. La constante vibración molecular y su comunicación a través de ondas resonantes crean sincronías entre las partes o elementos, sea un átomo, un organismo o una galaxia. (Lazlo, 2008; Mc. Taggart, 2009).

16 “El viento que el cielo derrumbó el agua”. Traducción al castellano de la autora. 


\section{Bibliografía}

Calvo, C. (2006), Del mapa escolar al territorio educativo. Disoñando la escuela desde la educación. Nueva Mirada, Chile.

Ídem (2009), "Los procesos educativos y la emergencia de complejidades caóticas y autoorganizadas”. Revista Acción Pedagódica n 18 / Enero Diciembre, pp.06 - 19.

Carlos Calvo y Antonio Elizalde, «Educación: creación de nuevas relaciones posibles», Polis [En línea], 25 | 2010, Puesto en línea el 10 febrero 2011, consultado el 03 marzo 2014. URL : http://polis.revues.org/292

Ídem «Complejidades educativas emergentes y caóticas», Polis [En línea], 25 | 2010, Puesto en línea el 23 abril 2012, consultado el 03 marzo 2014. URL : http://polis.revues.org/308 ; DOI : 10.4000/polis.308

Capra, F. Steindl-Rast, D. (1994), Pertenecer al Universo. Encuentros entre Ciencia y Espiritualidad. Edaf, Madrid.

Catalán, J. (2010), Teorías Subjetivas. Aspectos Teóricos y prácticos. Editorial Universidad de La Serena, La Serena - Chile.

Csikszentmihalyi, M. (2011), Creatividad. El fluir y la psicología del descubrimiento y la invención. Paidós Transiciones, Barcelona.

Del Ré, A. (1998), “Compreensão e produção de metáforas por crianças pré-escolares: relato de uma experiência”. Tese de mestrado em Lingüística. Universidade de São Paulo, São Paulo.

Ídem (2004), “Movimiento de Mise em Mots e a produção de metáforas face ao desenho”. Revista Alfa. São Paulo, 48(1):73-82.

François, F. (1993), Pratiques de l'oral. Nathan, Paris.

Gardner, H.; Winner, E. (1992), “O desenvolvimento da competência metafórica: implicações para as disciplinas humanísticas”. Da metáfora. Trad. de Lenita R. Esteves: 127-144.

Gardner, Howard. (1997), La mente no escolarizada. Cómo piensan los niños y cómo deberían enseñar las escuelas. Paidós, Buenos Aires.

Guillaumín, Arturo y Ochoa, Octavio. (2009), Hacia otra Educación. Miradas desde la complejidad. Arana Editores, México.

Gladwell, M. (2008), Inteligencia intuitiva. Ed.Taurus.

González, J. y Illescas, J. (2002), Acerca de la educación en el mundo originario Preinca. En el territorio donde se formaría el Tahuantinsuyo y el 
Qollasuyo. CEDIB, Bolivia.

Gopnik, A. (2010), El filósofo entre pañales. Ediciones Temas de hoy, Madrid.

Huizinga, J. (2008), Homo Ludens. Alianza Editorial, Madrid.

Jullien, F. (2006), Conferencia sobre la eficacia. Katz Editores, Buenos Aires.

Kant, I. (1938), Crítica de la razón pura. Ediciones Colihue SRL.

Lakoff, G. y Johnson, M. (1980), Metáforas de la vida cotidiana. Madrid: Cátedra.

Laszlo, E., Grof. S, Russell. P. (2000), La Revolución de la Conciencia. Kairós, Barcelona.

Laszlo, E. (2008), A ciência e o Campo Akáshico. Cultrix, São Paulo.

Ídem (2009), El Cambio Cuántico. Kairós, Barcelona.

Maturana, H. y Varela, F. (2007), El árbol del conocimiento. Editorial Universitaria, Santiago de Chile.

Max-Neef, M.; Elizalde, A. y Hopenhayn, M. (1986), Desarrollo a escala humana. Conceptos, aplicaciones y algunas reflexiones. CEPAUR, Santiago.

Mc Taggart, Lynne. (2009), El Experimento de la intención. Editorial Sirio S.A., Málaga.

Moreno, A. y Calvo, C. (2010), “Etnoeducación, educación física y escuela: transitando desde la educación informal a la escuela autoorganizada”. Revista Ágora: para la educación física y el deporte nº12 (2) mayo-agosto 2010, 131-150 / ISSN 1578-2174 / EISSN: 1989-7200.

Morin, E. (1990), Introducción al pensamiento complejo. Gedisa, Barcelona.

Ídem (1999), Los siete saberes necesarios para la educación del futuro. UNESCO, Paris.

Nicolescu, Basarab. (1999), O manifesto da transdisciplinaridade. Triom, São Paulo.

Sabaj Meruane, O. (2008), “Tipos lingüísticos de Análisis del Discurso (AD) o un intento preliminar para un orden en el caos”. RLA. Revista de lingüística teórica y aplicada, 46(2), 119-136. 
Vasilachis de Gialdino, I. (2009), Los fundamentos ontológicos y epistemológicos de la investigación cualitativa. Forum Qualitative Sozialforschung / Forum: Qualitative Social Research, 10(2), Art. 30. Revisado el 10/12/12 en http://www.qualitative-research.net/index.php/fqs/ article/view/1299/2778.

Wilber, Ken. (2000), Una Teoría de Todo. Editorial Kairós S.A., Barcelona.

Wild, P. (2001). El estar siendo-ocurriendo siempre no más. Sabiduría inca del sentimiento.

Wolcott, H. F., (1975), “Criteria for an ethnographic approach to research in schools”, Human Organization, vol. 34, n 2, 111-127.

Yin, R. K. (1989), “Case study research: Design and methods”. Applied Social Research Series, Vol. 5. London: Sage.

Ídem (1993), “Applications of case study research”. Applied Social Research Series, Vol. 34. London: Sage.

Recibido: 21.08.2913

Aceptado: 03.03.2014 